\title{
A contribuição da filosofia de Gaston Bachelard na educação para a imaginação
}

\author{
The contribution of Gaston Bachelard's philosophy to \\ education for the imagination
}

Alberto Filipe Araújo (Da

ROGÉRIO DE ALMEIDA (iD b

\section{Resumo}

O objetivo deste artigo é propor, em confluência com a filosofia de Gaston Bachelard, uma pedagogia do não inspirada na figura do cogito do sonhador para refletir sobre uma educação para a imaginação. Parte-se da filosofia do não de Bachelard para a construção de uma pedagogia do não, expressa como pedagogia do diálogo, que põe em relação complexa e complementar o conceito e a imagem, como prolongamentos do racionalismo aberto e da imaginação criadora. Na sequência, o cogito do sonhador é evocado para o estudo do devaneio e do imaginário, no quadro da imaginação material dos quatro elementos (terra, água, fogo e ar). Esses passos preambulares são necessários para se chegar à educação para a imaginação, cuja dimensão de Bildung se opera por meio da eufemização. Como função da imaginação, a eufemização tende a transfigurar o sofrimento, a morte e o nada em algo aceitável, não como negação, mas como dinamismo prospectivo que tenta melhorar a situação do homem no mundo. Exemplo desse dinamismo são as imagens literárias, com a polissemia e a polifonia que as caracterizam e as alçam ao domínio do estranho e da transgressão em relação à ordem do sentido primário. Desse modo, intenta-se mostrar como a pedagogia do não e o cogito do sonhador se articulam na proposição de uma educação para a imaginação pautada pela função de eufemização. São convocadas para este estudo, além da já mencionada filosofia de Gaston Bachelard, as contribuições teóricas de Gilbert Durand e Jean Jacques Wunenburger.

\footnotetext{
a Universidade do Minho, Braga, Portugal. Doutor em Educação, e-mail: afaraujo@ie.uminho.pt

b Universidade de São Paulo (USP), São Paulo, SP, Brasil. Doutor em Educação, e-mail: rogerioa@usp.br
} 
Palavras-chave: Filosofia da Educação. Filosofia do Não. Cogito do Sonhador. Imaginário.

\begin{abstract}
The aim of the article is to propose, in confluence with Gaston Bachelard's philosophy, a pedagogy of no, inspired in the figure of the dreamer's cogito to reflect about an education for the imagination. Bachelard's philosophy of no is the basis for the construction of a pedagogy of no, expressed as a pedagogy of dialogue, which puts the concept and image in a complex and complementary relationship, as extensions of open rationalism and creative imagination. Then, the dreamer's cogito is evoked for the study of reverie and the imaginary, within the framework of the material imagination of the four elements (earth, water, fire and air). These preambular steps are necessary to reach education for the imagination, whose dimension of Bildung operates through euphemisation. Like function of the imagination, euphemization tends to transform suffering, death and nothingness into something acceptable, not as denial, but as a prospective dynamism that tries to improve the situation of man in the world. An example of this dynamism are literary images, with the polysemy and polyphony that characterize them and elevate them to the domain of the stranger and transgression in relation to the order of the primary sense. In this way, we intend to show how the pedagogy of no and the cogito of the dreamer are articulated in the proposal of an education for the imagination guided by the function of euphemization. In addition to the aforementioned philosophy of Gaston Bachelard, the theoretical contributions of Gilbert Durand and Jean Jacques Wunenburger are invited for this study.
\end{abstract}

Keywords: Philosophy of Education. Philosophy of No. Pedagogy of No. Dreamer's Cogito. Imaginary.

\title{
Introdução
}

Neste artigo, trataremos de uma educação para a imaginação a partir de uma pedagogia do não e da figura do cogito do sonhador, de acordo com as perspectivas de Gaston Bachelard e Gilbert Durand. O objetivo é identificar as "afinidades eletivas” (Goethe) que a relação entre conceito e imagem escondem no seu diálogo complexo e nem sempre visível: o conceito (Animus) tende a objetivar a imagem (Anima) e esta, por sua vez, tende a subjetivá-lo e tudo se passa na esfera do cogito do sonhador (BACHELARD, 1984, p. 124-147), em cuja esfera há tanto lugar para a imaginação 
como para a consciência, ainda que matizada, aberta a uma subjetividade sensível à "tonalidade do ser" (1984, p. 144).

Sob o signo do racionalismo aberto e da imaginação criadora, tecidos pelos pares razão-imaginação e conceito-imagem, interpretamos a obra de Bachelard como potencialmente fecunda para perspectivar uma complementaridade entre conceito e imagem e pensar uma educação para a imaginação, isto é, que busca formar o sujeito para tornar-se mais imaginativo.

Com este substrato, o artigo organiza-se em duas partes: na primeira, abordamos a pedagogia do não — devedora da filosofia do não de Gaston Bachelard (1940) — como uma pedagogia do diálogo entre pensamento (ciência — logos — animus) e imaginação (cosmologia poética — mythos — anima); são, como aliás admite o próprio Bachelard, “duas disciplinas difíceis de equilibrar” (1984, p. 152), mas é este precisamente o nosso desafio. Na segunda parte, refletimos sobre a possibilidade de, na base do cogito sonhador e da função eufemizadora da imaginação, pensarmos uma educação para a imaginação.

\section{Da filosofia do não à pedagogia do não}

Uma pedagogia próxima da Philosophie du Non (1940) de Gaston Bachelard parece-nos a mais adequada para dar conta do par imaginação-imaginário, pois oferece um conjunto de orientações pertinentes para se pensar uma Pedagogia do não capaz de ajudar a formar o educando na via da imaginação. Reconhecendo, com Bachelard, que os eixos da poesia e da ciência são inversos, o que se espera de uma Pedagogia do não é que esta contribua para que sejam complementares e unidos "como dois contrários bem-feitos”. Espera-se, assim, que este modelo de pedagogia seja capaz de simultaneamente aceitar e ultrapassar a antipatia original entre o "espírito poético expansivo e o espírito científico taciturno" (BACHELARD, 1994, p. 12).

A formação do sujeito imaginante, entendida como Bildung, requer o que Georges Jean (1983, p. 193-199) chamou de "a dupla cultura continuada": um tipo de cultura capaz de iniciar o sujeito (o aluno e o professor) a conviver simultaneamente na via poética, literária (o domínio da imagem e do onirismo poético) e na via científica 
(o domínio do conceito e racionalismo aberto). Na mesma linha, vão igualmente as palavras de Bruno Duborgel (1995, p. 310; p. 317):

O NEP [Novo Espírito Pedagógico] da imaginação poética e o NEP da objectividade científica convergem e divergem a partir de um único acto de recusa absoluta, graças ao qual podem fazer desabrochar, no sujeito embrenhado na dupla via do conhecimento, a representação 'estética' e a realidade objectiva do mundo. [...] Apontando, através dos seus dois vectores paradoxais, ao mesmo tempo para a formação do conhecimento objectivo e para a construção do psiquismo imaginante, o NEP destina o sujeito da educação a uma dupla 'plenitude' e convida-o para uma criação dupla do seu eu e do mundo.

Neste contexto, consideramos que a pedagogia do não se afirma como uma pedagogia do diálogo, que procura transitar entre regimes diferentes da psique (os polos diurno e noturno), como uma espécie de retificação do saber pedagógico. Deste modo, representa um contributo heterodoxo para alargar os quadros desse mesmo tipo de conhecimento ao nível da sua extensão e da sua profundidade; é encarada como complemento inovador de um pensamento pedagógico e educativo já sistematizado. A Pedagogia do não deve aproveitar todos os momentos não só de trabalhar os conceitos próprios da tradição educativa, como igualmente dar uma maior atenção às imagens literárias, hortícolas, do crescimento, orgânica, artística (o caso da escultura e mesmo da pintura), da viagem, rítmicas, do par modelagemplasticidade da alimentação, do mobilar, do enchimento, do par depósito-depositário — que reenvia para a "educação bancária” (FREIRE, 1975, p. 79-107) - e do par da luz-trevas, entre outras, que sempre estão presentes no seio do discurso pedagógico e educativo em geral (CHARBONNEL, 1991-1993; HAMELINE, 1986, p. 141-166 e p. 182-186, 2000, p. 49; SCHEFFLER, 2003, p. 73-88).

A pedagogia do não busca, então, o trânsito entre as extremidades psíquicas, como um tipo de pedagogia polar (de duplo polo), o que significa que ela carece de um desenvolvimento dialético, "porque cada noção se explica de uma maneira complementar na base de dois pontos de vista filosóficos diferentes" (BACHELARD, 1973, p. 5). Não se trata de uma posição dualista de exclusão unilateral de um dos polos em questão (imagem ou conceito), mas da afirmação da vitalidade epistemológica entre imagem e conceito enquanto polos complementares: a imagem prolonga e completa o conceito e vice-versa. É, pois, uma pedagogia aberta 
inseparável do "racionalismo aberto" (BACHELARD, 1970, p. 4, 2013, p. 179), que, ao pensar a "coesão antagonista" do conceito com a imagem, envereda por um território desconhecido cujas consequências são difíceis de antever.

Por isso mesmo se arrisca a contradizer a tradição de uma pedagogia positivista e cientificizante para afirmar um "Novo Espírito Pedagógico” (DUBORGEL, 1995, p. 306-319). A Pedagogia do não é por isso mesmo uma pedagogia que, embora se alimente da tradição pedagógica e educativa, se afirma como um pensar novo face aos "lugares comuns" da pedagogia (HAMELINE, 2000, p. 23-36), o que não significa, contudo, que haja lugar para qualquer tipo de obstinação epistemológica de caráter dogmático: "Mas esse não nunca é definitivo para um espírito que sabe dialetizar os seus princípios e constituir em si-mesmo novas espécies de evidência" e até mesmo de explicações (BACHELARD, 1973, p. 9-10).

Deste modo, a Pedagogia do não deve contribuir para determinar modificações profundas na tradição pedagógica que obstinadamente privilegia o conceito em detrimento da imagem, no sentido que lhe confere Bachelard (WUNENBURGER, 1997, p. 71-72), para antes se concentrar e comprometer-se em equilibrar dialeticamente "os eixos da poesia e da ciência", que "são inicialmente inversos" (BACHELARD, 1994, p. 12).

O esforço é de articular o espírito científico (conceito) com o espírito poético (a imagem), respeitando as suas próprias diferenças, numa "coesão antagonista de contrários” em ordem a uma “criatividade geral” (WUNENBURGER, 2012, p. 247259). Esta articulação é passível de ser melhor compreendida pela noção de dialética de sabor bachelardiano que consiste, segundo Jean-Jacques Wunenburger (2012, p. 40), em "associar intimamente análise e síntese, dissociação e unificação dos conteúdos". Uma coesão antagonista que acontece graças a uma dialética (lógica criativa) preocupada em mediar a oposição de contrários ou de pares contraditórios que integra, por sua vez, quer a dimensão abstrata do conceito (invenção conceitual), quer a dimensão sensível das imagens (criatividade imaginativa poética). Por outras palavras, trata-se de um pensamento dialético preocupado em estabelecer mediações, complementaridades e trocas mútuas em vista à superação de obstáculos que impeçam o encontro entre dimensões antagônicas ou contraditórias entre si 
(conceitual e imaginária), salvaguardando, no entanto, as diferenças próprias dessas mesmas dimensões:

Os eixos da poesia e da ciência são inicialmente inversos. Tudo o que a filosofia pode esperar é tornar a poesia e a ciência complementares, uni-las como dois contrários bemfeitos. É preciso, portanto, opor ao espírito poético expansivo o espírito científico taciturno, para o qual a antipatia prévia é uma saudável precaução (BACHELARD, 1994, p. 12).

A Pedagogia do não é, portanto, uma pedagogia do diálogo, da ressonância e do consenso que procura a coerência e a coesão entre os eixos antagonistas da atividade espiritual (BACHELARD, 1970, p. 1-11). Por isso mesmo, não é uma pedagogia negativa, mas da complexidade caraterizada por uma lógica não-aristotélica (1973, p. 105-134) e por uma epistemologia não cartesiana (2013, p. 139-183). É um tipo de pedagogia que se baseia num tipo de lógica devedora das lógicas do princípio do terceiro incluído (1990, p. 135-199) que, de acordo com Wunenburger (2002, p. 43 65), dá conta da natureza quer da "vida das imagens", quer do próprio símbolo.

Desse modo, é uma pedagogia que retoma as caraterísticas que Bachelard assinalou à sua Filosofia do Não: não há "vontade de negação" pois ela "não nega qualquer coisa, não importa quando, não importa como” (1973, p. 135); não apresenta uma atitude sistemática de contradição, pois não aceita a contradição interna; não se caracteriza por uma dialética a priori, o que a opõe à dialética hegeliana ou ao imperativo da regra. A Pedagogia do não carateriza-se, antes, pelo movimento indutivo que atende às "articulações bem definidas" e, por fim, procura contribuir para uma "reorganização do saber sobre uma base alargada" (1973, p. 135). A Pedagogia do não é sensível à ideia, à semelhança da Filosofia do Não, de que por detrás de um conceito se abriga uma imagem: "De um lado qualquer, o que se subtrai da imagem deve encontrar-se no conceito retificado" (1973, p. 139).

Também a encaramos como uma pedagogia da ambiguidade: "propomos uma espécie de pedagogia da ambiguidade para dar ao espírito científico a flexibilidade necessária para a compreensão de novas doutrinas" (BACHELARD, 2013, p. 19). Enquanto pedagogia da ambiguidade, a pedagogia do não permite compreender a polarização epistemológica da relação entre conceito e imagem, em direção a uma síntese de contradições que resulta em algo novo - um "terceiro incluído" que é, por 
sua vez, fundado numa "razão contraditória" (WUNENBURGER, 1990). Este "terceiro incluído" surge como uma espécie de novidade filosófico-educacional, que relaciona os eixos da poesia e da ciência, unindo-os.

Contudo, como unir esses contrários sem a ajuda complexa dos conceitos de "ambiguidade", "intuição"1 e "oxímoro" (a dialetização através de paradoxos que muito convém e se ajusta à natureza simbólica própria da imaginação e do imaginário)? O conceito e a imagem, no seu duplo movimento dinâmico de contrários, tendem, não propriamente a uma síntese, mas a uma conciliação entre os polos heterogêneos que os perfazem, sem que as diferenças inerentes a cada um desses polos sejam apagadas. Visa-se, portanto, à superação da dualidade, sem que desapareçam as singularidades próprias da poesia-imagem e da ciência-conceito: "Conviria pois fundar uma ontologia do complementar menos asperamente dialética que a metafísica do contraditório” (BACHELARD, 2013, p. 20).

A ambiguidade indica a possibilidade de ampliação do significado ou sentido, enquanto o oximoro, como figura da retórica clássica, relaciona numa mesma expressão conceitos contrários que exprimem um sentido contraditório dinâmico e ativo. Ambos os conceitos se completam, se enriquecem mutuamente e nos protegem de cair na armadilha de perseguirmos "o conhecimento do simples em si, do ser em si, pois que é o composto e a relação que suscitam as propriedades, é a atribuição que esclarece o atributo" (BACHELARD, 2013, p. 165).

O conjunto destes conceitos é indissociável de uma lógica contraditorial (BEIGBEDER, 1973; LUPASCO, 1947; WUNENBURGER, 1990, p. 201-248), ou seja, não-aristotélica, que é a única capaz de compreender o sentido poliédrico que habita as imagens e que valoriza, por sua vez, o valor sintético da filosofia do não, cujo principal traço é o de operar na base de uma dialética que procura estabelecer uma harmonia tensional entre a racionalidade científica e o imaginário do devaneio. Por fim, defende a importância de uma "epistemologia não-cartesiana" para uma compreensão mais aprofundada da complexidade conceitual: "a epistemologia bachelardiana abandona assim as categorias aristotélica e cartesiana para se instalar

\footnotetext{
${ }^{1}$ Bachelard reconhece que o conhecimento científico é um conhecimento duplo: "Ele é simultaneamente intuição sensível e intuição intelectual" (1970, p. 22). 
numa heurística paradoxal” (WUNENBURGER, 2012, p. 44). Abre-se, assim, caminho para a conjugação de conceitos opostos que se relacionam no seio de uma dialética do sim e do não, o que introduz, por conseguinte, a pertinência dos princípios de complementaridade, contradição e não-identidade. A Philosophie du Non, mais do que construir uma lógica da contradição, privilegia uma desmultiplicação e uma complementaridade de conceitos — numa prática intelectual que visa à unificação progressiva, à integração sucessiva, enfim à coordenação de conceitos - com o objetivo de enfraquecer a hegemonia da lógica da identidade no seio das ciências.

Vários caminhos, então, podem ser trilhados a partir da pedagogia do não: o da imaginação e metáfora, o da educação científica e poética, o de uma lógica da imaginação, uma orientação ética das imagens, o valor da imaginação material e da imaginação formal, a exploração da vida e morte das imagens, enfim a abordagem da criatividade ou da transfiguração imaginativa (WUNENBURGER, 2012). Dentre esses caminhos, elegemos o que nos conduz ao cogito do sonhador que, de uma forma ou de outra, sintetiza a preocupação de compreender, na perspectiva bachelardiana, como se pode educar para a imaginação.

\section{O cogito do sonhador e a função de eufemização}

A figura do cogito sonhador é tratada por Bachelard na sua Poétique de la Rêverie em que o autor procurou "estudar o devaneio idealizante, um devaneio que coloca na alma de um sonhador valores humanos, uma comunhão sonhada de animus e de anima, os dois princípios do ser integral" (1984, p. 79). Assim, Bachelard chama-nos a atenção para a importância do cogito do sonhador que repousa numa espécie de vaivém contínuo entre a Psique diurna (gramática do dia) e a Psique noturna (gramática da noite): "É certamente difícil traçar a fronteira que separa os domínios da Psique noturna e da Psique diurna, todavia essa fronteira existe. Há dois centros de ser em nós, porém o centro noturno é um centro de concentração vaporoso. Não é um ‘sujeito"' (1984, p. 127). Aquilo que interessa realmente a Bachelard é

o homem desperto, o homem que as ideias acordam, o homem que a imaginação convida à sutileza. [...] o sonhador de sonho noturno é uma sombra que perdeu o próprio eu, o 
sonhador de devaneio, se for um pouco filósofo, pode, no centro do seu eu sonhador, formular um cogito. [...] O ser do sonhador de devaneios se constitui pelas imagens que ele suscita. A imagem nos desperta do nosso torpor, e esse despertar se anuncia num cogito. [...] Uma valorização a mais e eis-nos em presença do devaneio positivo, de um devaneio que produz, de um devaneio que, qualquer que seja a fraqueza daquilo que ele produz, bem pode ser denominado devaneio poético. Nos seus produtos e no seu produtor, o devaneio pode receber o sentido etimológico da palavra poético. $O$ devaneio reúne o ser em torno do seu sonhador. Dá-lhe ilusões de ser mais do que ele é. Assim, sobre o menos-ser que é o estado de relaxamento no qual se forma o devaneio se desenha um relevo - um relevo que o poeta saberá inflar até torná-lo um mais-ser. 0 estudo filosófico do devaneio convida-nos a nuances de ontologia. E esta ontologia é fácil, porque é a ontologia do bem-estar - de um bem-estar na medida do ser do sonhador que sabe sonhá-lo. Não existe bem-estar sem devaneio. Nem devaneio sem bem-estar. Assim, pelo devaneio, descobrimos que o ser é um bem. Um filósofo dirá: o ser é um valor (1984, p. 129-131).

O devaneio é uma atividade onírica na qual, de um modo ou de outro, o eu sonhador ainda está ainda consciente e bem posicionado para não só entender a sua oposição ente o polo diurno (abstração racional) e o polo noturno (imaginação material dos quatro elementos), como também incentivar a sua religação. Neste sentido, podemos melhor compreender que a imaginação, para Bachelard, não é uma faculdade do irreal, mas antes do sobrerreal, graças ao devaneio engendrado pelo cogito do sonhador que, como o vimos, afasta-se do mero sonho noturno (fluxo de imagens espontâneo e desordenado), sob o domínio das forças obscuras e anárquicas, impulsivas e involuntárias do inconsciente individual, para antes privilegiar o devaneio poético com as suas raízes no inconsciente coletivo com os seus arquétipos, muito especialmente o par animus-anima.

O sujeito imaginante, sob o signo do cogito sonhador como inspirador de ficções e de obras inspiradas, por exemplo, num jogo de imagens eufemizantes da vida e da morte, sente-se, por um lado, mais perto de uma poética cósmica, das imagens e símbolos que valem a pena e, por outro lado, mais próximo do seu destino e de assumir uma nova orientação de ser. O cogito do sonhador torna-se mais expansivo, mais significativamente criativo na medida em que, ao reunir em si as "ideias motrizes do espírito" responsáveis pela formação dinâmica das representações abstratas (domínio do conceito) e as representações simbólicas, metafóricas ou alegóricas (domínio da imagem) (WUNENBURGER, 2012, p. 254-259), afirma-se já como uma esperança auspiciosa para equilibrar a disciplina dedicada aos devaneios e a disciplina dedicada aos pensamentos. 
Contudo, seria possível dar conta dessa dimensão onírica do "cogito" sem evocar a imaginação? Pensamos seriamente que para bem devanear é preciso que o sujeito não somente esteja receptivo, como igualmente conviva e se comprometa (BACHELARD, 1972) com o fluxo de imagens diurnas (polo diurno da psique: via da abstração racional do espírito que carateriza a ciência abstrata do mundo) e noturnas (polo noturno da psique: via da imaginação poética, espontânea que carateriza o devaneio concreto sobre a Natureza) que anima a sua psique numa espécie de confluência malhada (pensamos na L'âme Tigrée de Gilbert Durand). Ambos os polos, na sua oposição antagonista, constituem a imaginação:

Pretende-se sempre que a imaginação seja a faculdade de formar imagens. Ora ela é antes a faculdade de deformar as imagens fornecidas pela percepção, ela é sobretudo a faculdade de libertar-nos das primeiras imagens, de mudar as imagens. [...] O vocábulo fundamental que corresponde à imaginação não é imagem, mas imaginário. O valor de uma imagem mede-se pela extensão da sua auréola imaginária. Graças ao imaginário, a imaginação é essencialmente aberta, evasiva. É ela, no psiquismo humano, a própria experiência da abertura, a própria experiência da novidade (BACHELARD, 2004, grifos do autor, p. 5-6).

A imaginação não é, como o sugere a etimologia, a faculdade de formar as imagens da realidade; ela é a faculdade de formar as imagens que ultrapassam a realidade, que cantam a realidade. Ela é uma faculdade de sobre-humanidade. [...] A imaginação inventa mais que as coisas e os dramas, ela inventa a nova vida, ela inventa do novo espírito; ela abre os olhos que têm novos tipos de visão. Ela verá se ela tem 'visões'. Ela terá visões se ela se educa com os devaneios antes de educar-se com as experiências, se as experiências funcionam em seguida como provas dos seus devaneios (BACHELARD, 1993, grifo do autor, p. 25).

Gaston Bachelard distingue dois tipos de imaginação: uma formal e outra material. A primeira dá vida à causa formal, enquanto a segunda dá vida à causa material: "a imaginação é uma função primeira do psiquismo humano, uma função de ponta, com a condição, claro, de considerar a imaginação com os seus três carateres formal, material e dinâmico" (1992, p. 392). Ambas as imaginações representam duas formas diferentes do espírito se manifestar e a cada uma delas corresponde uma forma imaginante diversa. Assim, à imaginação material corresponderá a força imaginante da novidade, do pitoresco, da variedade do acontecimento inesperado. Quanto à imaginação formal, ela está vocacionada para perscrutar o fundo do ser para nele encontrar simultaneamente o primitivo e o eterno (BACHELARD, 1976, p. 1-2). A 
imaginação criadora é, assim, uma faculdade do sobrerreal ou do irreal e como tal pode conceber aquilo que o autor designou de "imagem imaginada":

A ela pertence esta função do irreal que é psiquicamente tão útil quanto a função do real tão frequentemente evocada pelos psicólogos para caracterizar a adaptação de um espírito a uma realidade marcada pelos valores sociais. Esta função do irreal irá reconhecer os valores da solidão. O devaneio comum é um de seus aspetos mais simples. Mas teremos muitos outros exemplos da sua atividade se se quiser eficazmente seguir a imaginação imaginante em busca de imagens imaginadas (1992, p. 3-4).

Não vemos como é que uma educação para a imaginação se possa furtar ao diferente, à novidade, ao infinito de possibilidades outras (recordando aqui a dimensão do imaginário nos seus diferentes matizes: o utópico por exemplo), enfim, como poderá escapar ao apelo, ao chamamento do algures? E aqui cruzamo-nos com a função da eufemização e com os seus poderes baseados, entre outras possibilidades, nas figuras da retórica das quais destacamos, na linha de Gilbert Durand, o par antítesehipérbole no quadro do regime diurno da imagem (estruturas heroicas ou esquizomorfas): “A imaginação eufemiza pela hipérbole e a antítese conjugadas, e mesmo quando ela representa hiperbolicamente as imagens do tempo, é ainda para exorcizar o tempo e a morte que ele traz em si" (1984, p. 487); assim como realçamos a antifrase no quadro do regime noturno da imagem (estruturas místicas do imaginário): "Quanto às estruturas místicas, elas dão-nos a conhecer o estilo da antífrase, do eufemismo propriamente dito. [...] Mas o estilo da antífrase conserva o traço semântico do processo de dupla negação, ele representa o triunfo estilístico da ambivalência, do sentido duplo" (1984, p. 488). A função da eufemizạ̧ão tem a ver com a transmutação, com a transfiguração, com a transformação do horrendo, do monstruoso, do sofrimento em algo de mais aceitável, em algo mais razoável do ponto de vista humano: ela assume-se, portanto, como uma esperança graças às imagens da verticalidade que são imagens que dispõem de "um coeficiente de equilíbrio, de libertação e de felicidade" (WUNENBURGER, 2012, p. 212). Este tipo de imagens em muito contribui para exorcizar as imagens das trevas e da queda que estão, por sua vez, ligadas não somente a uma psicologia da gravidade (BACHELARD, 1992, p. 342-402) como também à "queda imaginária" no quadro de uma imaginação do movimento (2004, p. 117-141). A diversidade ligada às imagens da verticalidade, aéreas, contrapõe-se às imagens das trevas e da queda através dos devaneios de 
ascensão que implicam necessariamente as imagens aéreas ligadas à verticalidade, ao sonho do voo, à imaginação do movimento e, por fim, ao crescimento psíquico (BACHELARD, 2004).

Nesta linha também cabe uma palavra para a "vida e morte das imagens" que nos conduz ao tema da função de eufemização da imaginação no pensamento bachelardiano (WUNENBURGER, 2012, p. 231-246), particularmente quando JeanJacques Wunenburger se refere praticamente às imagens que ajudam a "exorcizar a morte" (2012, p. 237-240). Essas imagens, lendo Bachelard, especialmente La terre et les rêveries de la volonté (1992) e L'Air et les Songes (2004), opõem-se àquelas que caraterizam a "Psicologia da Gravidade" (BACHELARD, 1992, p. 341-402), que são imagens pessimistas, das trevas, de cariz negativo, de vazio e de fracasso: caraterísticas de certas imagens terrestres que caraterizam o modo de ser daqueles sujeitos pesados, lentos e deprimidos, introvertidos que vivem sob o signo da queda, do abismo, do inferior, da vertigem e do baixo:

A experiência da vertigem e do seu cortejo de imagens ameaçadoras revela a Bachelard que o ser não se reduz a uma força criadora que anima o onirismo feliz, mas que está, no seu centro, acima de uma espécie de vazio original, de um buraco do ser, o que explica a fragilidade, a solidão e a angústia (WUNENBURGER, 2012, p. 238).

Em contrapartida, há outro complexo de imagens ligado à "psicologia ascensional" (2004, p. 16), que é produto de uma imaginação do movimento, relacionada ao superior, à luz, à verticalidade, à arte de voar e às alturas. O que faz com que elas sejam naturalmente ligeiras, leves, aéreas, do alto, enfim ligadas ao voo e à sua dinâmica própria e ao tipo de sujeitos extrovertidos e espiritualmente ativos. O simbolismo do voo exprime aquela dimensão da imaginação "caraterizada por uma força ascensional que alarga a esfera do $\mathrm{Eu}$, que o faz participar nos objetos metamorfoseados pelas valências meta-físicas, suprassensíveis despertadas pelo devaneio" (2012, p. 238). Poderíamos, então dizer com Wunenburger, que as imagens ligadas preponderantemente à verticalidade, à luz, ou seja, à claridade constituem "a primeira via para suportar uma angústia primária que resulta de um não-sentido ontológico" (2012, p. 239) que, aliás, a experiência da própria morte, do vazio existencial, do nada e mesmo da indeterminação parecem representar: "No limite, os 
sonhos absolutos mergulham-nos no universo do Nada" (BACHELARD, 1984, p. 125). Assim, podemos afirmar que os devaneios de ascensão, da verticalidade, aéreos, tal como Bachelard nos ensinou a propósito da imaginação dinâmica do movimento, aérea ou da altura, especialmente em L'Air et les Songes (2004, p. 80-81), parecem explicar, por sua vez, aquilo que Gilbert Durand denomina de função eufemizadora da imaginação:

função de eufemização, não um simples ópio negativo, máscara que a consciência ergue face à horrenda figura da morte, mas pelo contrário dinamismo prospectivo, que através de todas as estruturas do projecto imaginário, tenta melhorar a situação do homem no mundo. [...] o facto de que a morte é negada, é eufemizada em extremo numa vida eterna, no interior das pulsões e das resignações que inclinam as imagens para a representação da morte. $O$ facto de desejar e de imaginar a morte como um repouso, um sono, esse mesmo facto a eufemiza e a destrói (DURAND, 1979, p. 121-122).

No mesmo sentido, Durand, nas suas Les Structures Anthropologiques de L'Imaginaire (1969), a propósito da função fantástica, como função primordial do Espírito e que já integra em si a memória como uma espécie de muralha contra o tempo, escreve o seguinte:

Mas se a memória tem o caráter fundamental do imaginário, que é a de ser eufemística, é também, pela mesma razão, anti-destino e opõe-se ao tempo. [...] Longe de fazer a apologia do tempo, a memória, como o imaginário, opõe-se às facetas do tempo, e assegura que o ser, contra a dissolução do devir, a continuidade da consciência e a possibilidade de retornar, de regressar, além das necessidades do destino. [...] É contra o nada do tempo que se ergue toda a representação, e sobretudo a representação em toda a sua pureza de anti-destino: a função fantástica de que a memória é apenas um incidente. A vocação do espírito é a insubordinação à existência e à morte, e a função fantástica manifesta-se como a patroa desta revolta. [...] O sentido supremo da função fantástica, erigida contra o destino mortal, é portanto o eufemismo. Quer dizer que há no homem um poder de melhorar o mundo. Mas esta melhoria não é, tampouco, vã especulação 'objetiva', visto que a realidade que emerge no seu nível é a criação, a transformação do mundo da morte e das coisas no da assimilação à verdade e à vida (DURAND, 1984, p. 467-472).

O exposto permite-nos pensar uma educação para a imaginação, não só sob o signo do cogito sonhador, como também sob a orientação de uma pedagogia do não que se escora em estratégias eufemísticas capazes de resistir, por intermédio da razão e da imaginação, ao declínio da educação, atingida por um mal-estar profundo marcado pelas mais diversas taras e experiências pedagógicas que comprometem a libido educandi 
de uma educação que se pretende criticamente problematizadora (FREIRE, 1975, p. 79).

Ainda na perspectiva de Freire (1975, p. 79), o "homem como ser inconcluso" (1975, p. 79) jamais deverá perder a consciência da sua inconclusão e se assim é não deverá nunca abandonar o seu movimento permanente de "busca do ser Mais" (p. 106). E não será esta "busca do ser mais" já uma espécie de recherche du temps perdu (1906-1922) como Marcel Proust magistralmente escreveu? E se assim for, já por efeito de uma eufemização da imaginação tão desejada, não se converterá já esse tempo num feliz temps retrouvé (1927)? Parece-nos bem que sim, se acolhermos as palavras de Gilbert Durand como orientadoras da via propícia para achar esse mesmo "tempo reencontrado" encarado como um "suplemento de alma" e mesmo da memória:

Nesta função fantástica reside esse 'suplemento de alma' que a angústia contemporânea procura anarquicamente sobre as ruínas dos determinismos, porque é a função fantástica que acrescenta à objetividade morta o interesse assimilador da utilidade, que acrescenta à utilidade a satisfação do agradável, que acrescenta ao agradável o luxo da emoção estética, que, por fim, numa assimilação suprema, depois de ter semanticamente negado o negativo destino, instala o pensamento no eufemismo total da serenidade ou da revolta filosófica ou religiosa. E sobretudo, a imaginação é o contraponto axiológico da ação. [...] Por isso, o imaginário longe de ser paixão vã, é ação eufémica e transforma o mundo segundo o Homem de Desejo: A poesia é um piloto, Orfeu acompanha Jasão (DURAND, 1984, p. 500-501).

Todas estas considerações representam um avanço para melhor se compreender que a educação para a imaginação bem poderia ser chamada, como nos ensinou inspiradamente o poeta Manoel de Barros, de "didática da invenção":

O rio que fazia uma volta atrás de nossa casa era a imagem de um vidro mole que fazia uma volta atrás de casa. Passou um homem depois e disse: Essa volta que o rio faz por trás de sua casa se chama enseada. Não era mais a imagem de uma cobra de vidro que fazia uma volta atrás de casa. Era uma enseada. Acho que o nome empobreceu a imagem (BARROS, 2016, p. 13).

O nome empobrece a imagem porque espartilha a inovação semântica (um dos traços da metáfora) que lhe é própria ("Ela [a imagem literária] é polisemântica” — BACHELARD, 2004, p. 327), como que estrangula a sua novidade e surpresa semântica insuflada pelas "hormonas da imaginação" (2004, p. 19) que são os quatro 
elementos cósmicos: terra, ar, fogo e água. O nome é filho do conceito (função do real) enquanto a imagem é fruto da função do irreal (2004, p. 13):

Para merecer o título de imagem literária, é necessário um mérito de originalidade. Uma imagem literária é um sentido em estado nascente; a palavra - a velha palavra - recebe aqui uma nova significação. Mas isso ainda não basta: a imagem literária deve enriquecerse de um onirismo novo. Significar outra coisa e fazer sonhar de outro modo, tal é a dupla função da imagem literária (BACHELARD, 2004, p. 324).

E foi precisamente uma imagem literária portadora de um sentido novo, ou seja, figurado (sentido figurado: domínio do estranho e da transgressão), o domínio da metáfora (WUNENBURGER, 2012, p.103-114), uma palavra revestida de uma nova significação que Manoel de Barros nos trouxe distante já do sentido próprio (sentido primário: domínio do normal, do corrente e da ordem). Trouxe-nos, na verdade, uma imagem sonora ("Ela [a imagem literária] é polifónica” BACHELARD, 2004, p. 327), que apela a um onirismo que nos sobressalta, a uma imaginação que em nós murmura, e, por fim, a um pensamento que se pretende palavra escrita: “A imaginação encanta-se da imagem literária. A literatura não é portanto o sucedâneo de nenhuma outra atividade. Ela realiza um desejo humano. Ela representa uma emergência da imaginação" (2004, p. 324). Em toda a imagem literária sente-se o movimento dinâmico das palavras, que se organizam de modo a expressar a fala dos pensamentos entremeados com os fragmentos oníricos constituídos desde as imagens mais primitivas às imagens naturais, enfim as imagens originais ou primeiras como são o caso da árvore, da flor, da forja, do rochedo, do cristal, da imensidão cósmica ou da casa (WUNENBURGER, 2012, p. 106-109). Estas imagens acabam por imiscuir-se na literatura e na poesia e é transportada a um estatuto de novidade universal e interpelante:

A imagem literária é, portanto, tanto uma categoria como um acontecimento: chama-se literária a imagem que se encontra a meio-caminho do sonho e da imagem erudita, que é fonte de um grande número de metáforas que a constituem como um comentário; mas cada imagem literária, fruto de uma criatividade verbal, apresenta-se também como um jorro imprevisível, uma renovação única de imagens preexistentes, cuja forma mais elevada é a metáfora pura, reduzida a uma forma verbal concisa (WUNENBURGER, 2012, p. 108). 


\section{Considerações finais}

Desenvolvemos ao longo deste artigo duas ideias centrais: a primeira tratou da pedagogia do não, inspirada na Philosophie du Non de Bachelard, como aquele tipo de pedagogia que, através da orientação epistemológica dos conceitos que a estruturam, pode contribuir mais pertinentemente para educar o sujeito, que não necessariamente esteja na sociedade escolar, para compreender criativamente o universo da imaginação e da própria "poética do devaneio". Neste sentido, uma educação para a imaginação que torne o sujeito mais sensível à “vida das imagens" (WUNENBURGER, 2012, p. 231 246), sem contudo se esquecer da dimensão ontológica e ética, é naturalmente bemvinda e até desejada para criar uma Bildung (WUNENBURGER, 1993, p. 59-69) modelada pela imagem inspiradora da Fénix renascida: o pássaro mítico que morre no fogo antes de renascer para a vida. Uma imagem feliz que convide uma atitude pedagógica, que se pretenda remitologizadora, é assim indissociável do devaneio engendrado pelo "cogito" do sonhador. Por outras palavras, cabe a este tipo de educação ensinar o sujeito a conviver tranquilamente com a "tensão permanente entre a necessidade e a liberdade, entre a objetividade e a subjetividade” (2012, p. 213), assim como também desenvolver no "cogito" do sujeito uma sensibilidade ativa face ao conceito (espírito científico: esfera da abstração e da relação voluntarista e viril — animus) e à imagem (poética: esfera do concreto e da relação intimista - anima). E deste modo o ideal do "homem bidimensional" pode surgir animado por um paradigma educacional de dupla faceta que aceita a própria contradição como algo de natural e mesmo necessária — o ideal da "humanidade bifronte" de que fala JeanJacques Wunenburger (2012, p. 216-217).

A segunda ideia girou em torno do cogito do sonhador: é sob o seu signo, e de acordo com as orientações da pedagogia do não que se pode pensar a complementaridade entre o conceito e a imagem já não num clima de divergência de contrários, de oposição entre diurno e noturno, mas antes numa paisagem de convergência, onde o seu valor sintético nunca deixou de ser realçado, em ordem a uma educação para a imaginação simultaneamente sensível às formações científica e poética, à sociedade escolar e à solidão cósmica (WUNENBURGER, 2012, p. 208-211 e p. 214-217). Este 
tipo de educação, mediante a função da eufemização, assume-se como sendo sensível às "hormonas da imaginação", que são os quatro elementos (terra, água, fogo e ar), a fim de permitir assegurar ao sujeito imaginante uma criatividade pessoal, de modo que ele assuma a experiência da alteridade relativamente não apenas ao outro inseparável já da dimensão ética (2012, p. 219-230), como também face às experiências da própria vida.

\section{Referências}

BACHELARD, G. Le rationalisme appliqué. $4^{e}$ éd. Paris: PUF, 1970.

BACHELARD, G. L'engagement rationaliste. Paris: PUF, 1972.

BACHELARD, G. La philosophie du non. Essai d'une philosophie du nouvel esprit scientifique. $\sigma^{\mathrm{e}}$ éd. Paris: PUF, 1973.

BACHELARD, G. L'Eau et les Rêves. Essai sur l'imagination de la matière. $13^{\text {e }}$ Réimp. Paris: Librairie José Corti, 1976.

BACHELARD, G. La poétique de la rêverie. Paris: PUF, 1984.

BACHELARD, G. La Terre et les rêveries de la volonté. Essai sur l'imagination de la matière. $15^{\mathrm{e}}$ Réimp. Paris: José Corti, 1992.

BACHELARD, G. L'Ean et les Rêves. Essai sur l'imagination de la matière. Paris: Le Livre de Poche/Librairie José Corti, 1993.

BACHELARD, G. La psychanalyse du feu. Paris: Gallimard, 1994.

BACHELARD, G. L'air et les songes. Essai sur l'imagination en mowvement. Paris: Le Livre de Poche/Librairie José Corti, 2004.

BACHELARD, G. Le nouvel esprit scientifique. Paris : PUF, 2013.

BARroS, M. Poesia Completa. Lisboa: Relógio D’Água, 2016.

BEIGBEDER, M. La Contradiction et nowvel entendement. Paris: Bordas, 1973.

CHARBONNEL, N. La tâche avengle. Les Aventures de la Métaphore. V. 3. Strasbourg: PU de Strasbourg, 1991-1993.

DUBORGEL, B. Imaginário e Pedagogia. Trad. Maria João Batalha Reis. Lisboa: Instituto Piaget, 1995.

DURAND, G. Science de l'homme et tradition. Le nouvel esprit anthropologique. Paris: Berg International, 1979.

DURAND, G. Les Structures Anthropologiques de l'Imaginaire. Introduction à l'archétypologie générale. $10^{\grave{e}}$ ed. Paris: Dunod, 1984. 
FREIRE, P. Pedagogia do Oprimido. $2^{\mathrm{a}}$ ed. Porto: Afrontamento, 1975.

JEAN, G. Bachelard, L’Enfance et la Pédagogie. Paris: Éditions du Scarabée, 1983.

HAMELINE, D. L'Éducation, ses Images et son Propos. Paris: ESF, 1986.

HAMELINE, D. Courants et contre-courants dans la pédagogie contemporaine. Paris: ESF, 2000.

LUPASCO, S. Logique et Contradiction. Paris: PUF, 1947.

SCHEFFLER, I. Le langage de l'éducation. Trad. Michel Le Du. Paris: Klincksieck, 2003.

WUNENBURGER, J.-J. La raison contradictoire. Sciences et philosophie modernes : la pensée du complexe. Paris: Albin Michel, 1990.

WUNENBURGER, J.-J. La «Bildung» ou l'imagination dans l'éducation. In : BOUVERESSE, Renée (Textes réunis et publiés par). Education et philosophie. Écrits en l'honneur d'Olivier Reboul. Paris: PUF, 1993, p. 59-69.

WUNENBURGER, J.-J. Philosophie des images. Paris: PUF, 1997.

WUNENBURGER, J.-J. La Vie des Images. Grenoble: PUG, 2002.

WUNENBURGER, J.-J. Gaston Bachelard. Poétique des Images. Paris: Mimesis, 2012. 